\title{
THE IMPACT OF STEM CELLS ON DENTISTRY - A REVIEW
}

\section{Marry Singla ${ }^{1}$, Vinay Dua ${ }^{2}$, A Radhika Reddy ${ }^{3}$, Ashutosh ${ }^{4}$}

${ }^{1}$ PG Student, Department of Orthodontics \& Dentofacial Orthopaedics, MM College of Dental Sciences \& Research, Haryana, India ${ }^{2}$ Professor \& HOD, Department of Orthodontics \& Dentofacial Orthopaedics, MM College of Dental Sciences \& Research, Haryana, India ${ }^{3}$ Professor, Department of Orthodontics \& Dentofacial Orthopaedics, MM College of Dental Sciences \& Research, Haryana, India ${ }^{4}$ Sr. Lecturer, Department of Orthodontics \& Dentofacial Orthopaedics, MM College of Dental Sciences \& Research, Haryana, India

\begin{tabular}{|c|c|}
\hline $\begin{array}{r}\text { Corresponding Author: } \\
\text { Marry Singla } \\
\text { E-mail: merry2345@gmail.com } \\
\text { Received: } 21^{\text {st }} \text { February } 2015 \\
\text { Accepted: } 2^{\text {nd }} \text { August } 2014 \\
\text { Online: } 10^{\text {th }} \text { September } 2015\end{array}$ & 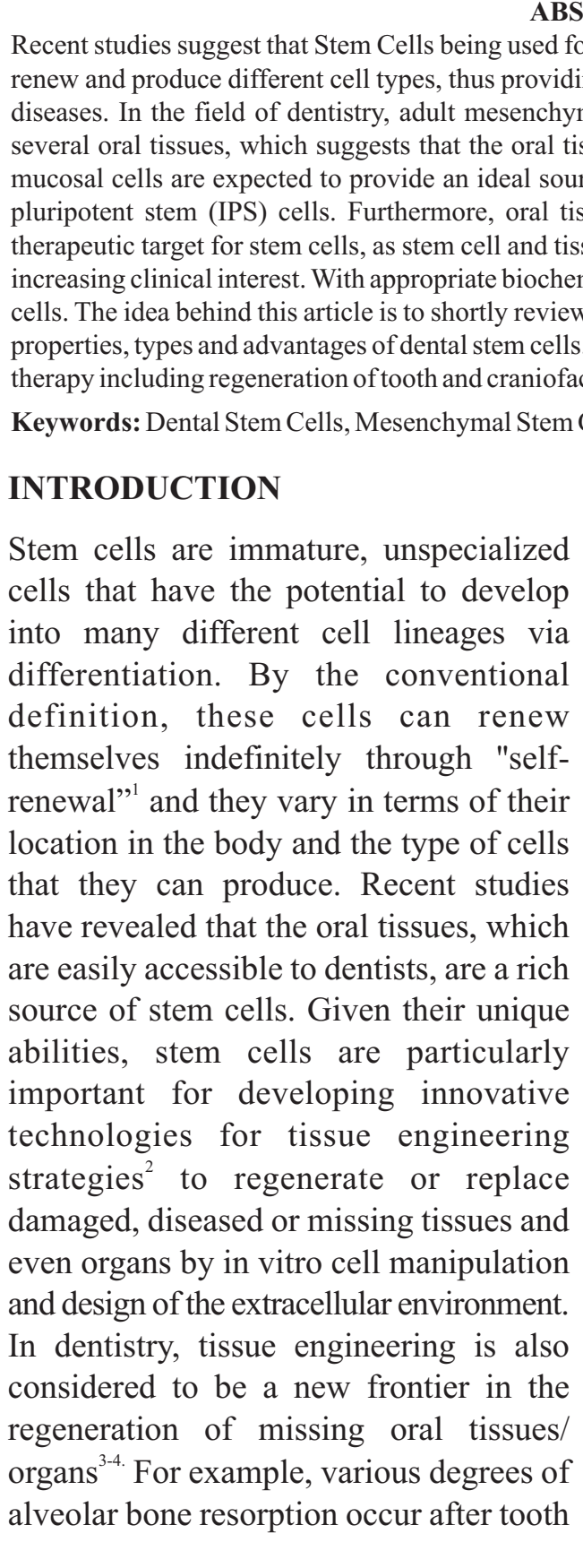 \\
\hline
\end{tabular}

ABSTRACT

Recent studies suggest that Stem Cells being used for a number of regenerative diseases. Stem cells can selfrenew and produce different cell types, thus providing new strategies to regenerate missing tissues and treat enchymal stem/stromal cells (MSCs) have been identified in review the obtained literature on stem cell with respect to their properties, types and advantages of dental stem cells. Emphasis has been given to the possibilities of stem cell therapy including regeneration of tooth and craniofacial defects.

\section{INTRODUCTION}

Stem cells are immature, unspecialized cells that have the potential to develop into many different cell lineages via differentiation. By the conventional definition, these cells can renew hemselves indefinitely through "selfof their ocation in the body and the type of cells that they can produce. Recent studies have revealed that the oral tissues, which source of stem cells. Given their unique abilities, stem cells are particularly mportant for developing innovative technologies for tissue engineering strategies $^{2}$ to regenerate or replace damaged, diseased or missing tissues and ment considered to be a new frontier in the regeneration of missing oral tissues/ alveolar bone resorption occur after tooth loss/extraction because of periodontal disease, severe caries, root fractures or accidental trauma. ${ }^{5}$ In addition, the bone resorption in the residual ridge, particularly in the mandible, continues throughout life in many edentulous patients. ${ }^{6}$ The severe bone resorption in edentulous areas makes it difficult to restore the missing teeth with dental implants or denture treatment ${ }^{7-9}$ (Figure 1). Therefore, stem cell and tissue engineering therapies are expected to provide a novel capability to regenerate large defects in periodontal tissues ${ }^{10}$ and alveolar bone ${ }^{11-13}$ and to ultimately replace the lost tooth itself. The tissues and organs targeted for such regenerative medicine strategies in dentistry include the salivary gland $^{14}$, tongue ${ }^{15}$ and craniofacial skeletal muscles, ${ }^{16}$ as well as the condylar cartilage of the temporomandibular joint. ${ }^{17}$ Many basic and translational studies with stem cells and the other key elements of tissue engineering, that is bioactive factors and extracellular matrix scaffolds have been conducted in animal 

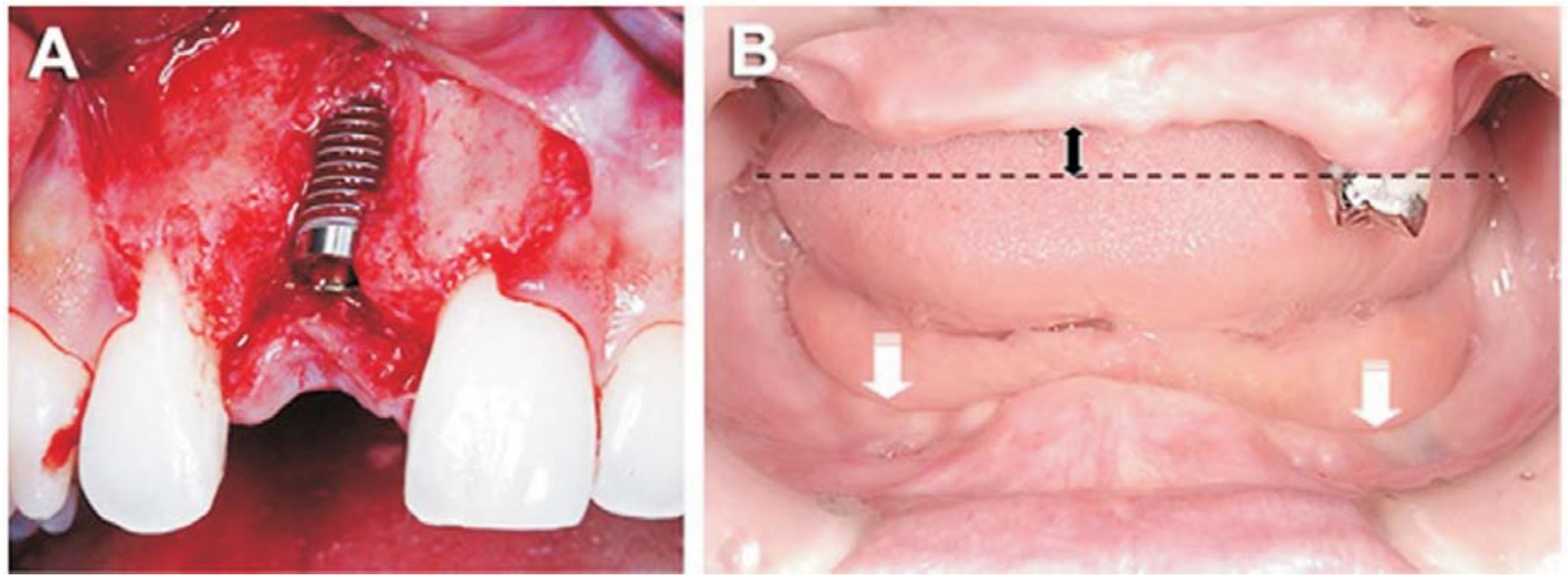

Figure 1

models to develop the concept of oral tissue and organ regeneration for clinical application in dentistry. In addition, stem cell-based tissue engineering has already been applied to clinical trials with demonstrated efficacy in orofacial bone tissue regeneration. ${ }^{11-13}$ Despite these promising successes, recent findings that various types of stem cells can be obtained may lead to confusion regarding the role of stem cells and regenerative biology in dentistry, particularly with regard to the optimal type of stem cells for oral tissue and organ regeneration. This review focuses on the types and derivation of stem cells in dentistry from the viewpoint of clinical availability. It will also discuss appropriate stem cell sources in dentistry with regard to their differentiation capacity, accessibility and the current state of stem cell research and clinical trials in dentistry.

\section{PROPERTIES, TYPES AND SOURCES OF STEM CELLS}

A stem cell should possess two properties namely selfrenewal and potency.

- Self-renewal is the capacity of the cell to undergo numerous cycles of cell division maintaining their undifferentiated state. ${ }^{18}$ An ideal stem cell should have the capacity of self renewal beyond the "Hayflicks" limit (the ability of the cell to proliferate to about 40-60 population doublings before it achieves senescence). ${ }^{19}$

- Potency means the differentiation capacity of the stem cell. $^{20}$
Stem cell types - Stem cells can be broadly divided into

1. Embryonic stem cell

2.Adult stem cell

- Hematopoietic stem cell

- Mesenchymal stem cell

3. Induced pluripotent stem cell

\section{Embryonic stem cell}

Embryonic stem cells are capable of multipotential differentiation but clinical feasibility is limited due to ethical issues. The inner cell mass (the part that would form fetus) of the embryo is used to form embryonic cell lines. ${ }^{21}$ Embryonic stem cells has a potential to differentiate into different germ layers namely ectoderm, endoderm and mesoderm. ${ }^{22}$ Tumorigenesis and immune rejection is common with embryonic stem cells.

\section{Adult stem cell}

Adult stem cells are multipotent stem cells. ${ }^{23}$ They can be harvested from different kind of tissues like bone marrow, umbilical cord, amniotic fluid, brain tissue, liver, pancreas, cornea, dental pulp, and adipose tissue. Adult stem cells are comparatively easier to isolate and do not have any ethical issues. Immune rejection and teratoma formation is also rare with adult stem cells. Adult stem cells are commonly used in current day practice.

\section{Induced pluripotent stem cell}

Induced pluripotent stem cells (IPS) is an evolving concept in which 3-4 genes found in the stem cells are 
transfected into the donor cells using appropriate vectors. ${ }^{24}$ The stem cells thus derived by culturing will have properties almost like embryonic stem cells. This path breaking discovery may have a major role in future stem cell therapy.

\section{Sources of stem cells}

The oral and maxillofacial region can be treated with stem cells derived from the following sources (Figure 2) differentiation ${ }^{25}$. Advantage of adipose tissue is that it is easily accessible and abundant in many individuals.

\section{Stem cells from the oro-maxillofacial region}

Stem cells from oral and maxillofacial region predominantly contain mesenchymal stem cells (MSCs). In oral and maxillofacial area different types of dental stem cells can be isolated and characterized. These include-

a) Dental pulp stem cells (DPSCs)

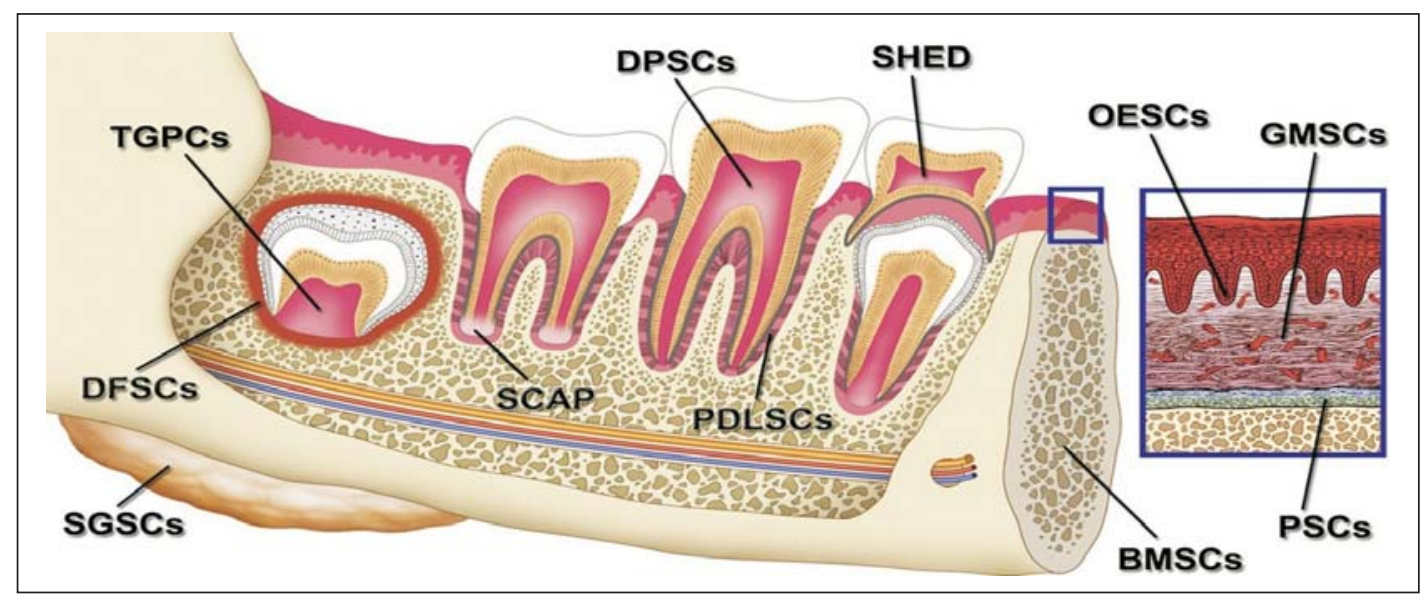

Figure 2

1. Bone marrow

\section{Adipose tissue}

\section{Stem cells from oral and maxillofacial region}

\section{Bone marrow}

Bone marrow stem cells (BMSCs) can be harvested from sternum or iliac crest. They are composed of both hematopoietic stem cells and mesenchymal stem cells (MSCs). The majority of oro-maxillofacial oral structures are formed from mesenchymal cells. Human BMSCs can also be isolated from orofacial (maxilla and mandible) bone marrow aspirates obtained during dental surgical procedures such as dental implant treatment, wisdom tooth extraction, extirpation of cysts and orthodontic osteotomy. The advantage of bone marrow is that it has a large volume of stem cells which can be differentiated into wide variety of cells. ${ }^{25}$

\section{Adipose tissue}

They can be harvested from the lipectomy or liposuction aspirate. Adipose derived stem cells (ADSCs) contain a group of pluripotent mesenchymal stem cells (MSCs) that exhibit multilineage b) Stem cells from exfoliated deciduous teeth (SHED)

c)Periodontal ligament stem cells (PDLSCs)

d)Stem cells from apical papilla (SCAP)

e)Dental follicle progenitor cells (DFPCs)

These dental stem cells have mesenchymal stem cells (MSCs) like qualities, such as self-renewal and differentiation potential. ${ }^{31}$

1. Dental pulp stem cells (DPSCs) ${ }^{26}:$ The regenerative capacity of the human dentin/pulp complex enlightens scientists that dental pulp may contain the progenitors that are responsible for dentin repair. Dentin pulp stem cells, generate a dentin, pulp like complex that is composed of mineralized matrix with tubules lined with odontoblasts. Studies have shown that these cells can differentiate into adipocytes and neural like cells. ${ }^{26}$

2. Stem cells from exfoliated deciduous teeth $(\mathrm{SHED})^{27}$ : Isolation of mesenchymal progenitors from the pulp of human deciduous teeth is termed as Stem cells from exfoliated deciduous teeth (SHED). These cells have higher proliferation rate as compared with stem cells from permanent teeth. 
Studies have shown that these cells can differentiate into neurons adipocytes, osteoblasts and odontoblasts. These cells have osteoinductive capacity, which can induce bone in vivo and can be differentiated into odontoblast like cells, which induce dentine formation. Because of their ability to generate neurons, and secrete neurotrophic factors, dental stem cells may also be beneficial for the treatment of neurodegenerative diseases and the repair of motor neurons following injury.

3. Periodontal ligament stem cells (PDLSCs) ${ }^{28}$ : These cells are isolated from root surface of extracted teeth and differentiate into cells or tissues which are very similar to periodontium. Studies on these cells transplanted into immunecompromised mice and rats demonstrated their capacity for tissue regeneration and periodontal repair. These cells can also differentiate into cells that can colonize and grow on biocompatible scaffold, suggesting that these cells can be autologous source of stem cells for bone tissue engineering in regenerative dentistry.

4. Stem cells from apical papilla (SCAP) ${ }^{29}$ : Dental stem cells isolated from human teeth found at the tooth root apex are known as Stem cells from apical papilla (SCAP). These cells can only be isolated at a certain stage of tooth development, but have a greater capacity for dentin regeneration than Dental pulp stem cells (DPSCs) because the dental papilla contain a higher number of adult stem cells compared to the mature dental pulp. Because of their higher proliferative capacity, they are suitable for inducing root formation. These cells can generate odontoblast like cells and produce dentin, thus help in formation of root dentine as in case of apexogenesis.

5. Dental follicle progenitor cells (DFPCs) ${ }^{30}$ : Dental follicle surrounding the developing tooth germ has long been considered a multipotent tissue, based on its ability to generate cementum, bone and periodontal ligament. Dental follicle precursor cells (DFPC) differentiate into osteoblasts/ cementoblasts, adipocytes, and neurons. These cells have good potential for use in tissue engineering applications, including periodontal and bone regeneration.

\section{Regeneration of craniofacial defects}

Stem cells can be useful in the regeneration of bone and to correct large craniofacial defects due to cyst enucleation, tumor resection, and trauma. The closure of a bone defect is commonly carried out with the transfer of tissue, which have disadvantages like, not able to restore the unique function of the lost part, donor site morbidity, accompanied by scarring, infection and loss of function. ${ }^{31-32}$ In a case report, Adipose derived stem cells was used to treat the calvarial defect $(120 \mathrm{~cm} 2)$ of a 7-year-old girl who had severe head injury. Autologous adipose stem cells were extracted from gluteal region along with iliac crest bone graft. Autologous fibrin glue that holds the cells in place was prepared by cryoprecipitation. This successful technique has given new rays of hope that ADSCs can be used for difficult reconstructive procedures. ${ }^{33}$

Soft tissue reconstruction in the oromaxillofacial region is of paramount importance when there is significant loss of soft tissues during surgery or trauma. Various methods including graft and flap transfer has been tried that produced donor site morbidity. Alhadlaq et $\mathrm{al}^{34}$ in their experimental studies found human MSCs can turn into adipose cells when they are exposed to adipogenic inducing medium. Adipose cells with appropriate shaped scaffold can be used for reconstruction of soft tissues.

Stem cells isolated from dental pulp has potential to differentiate into osteoblasts and are a good source for bone formation. Stem cells from oral and maxillofacial region can be combined with bone marrow stem cells to correct larger defects. Oromaxillofacial bone tissue repair with stem cells has been done using collagen sponge scaffold and dental pulp stem cells harvested from third molars of the same patient. Lagenbach et $\mathrm{al}^{35}$ in their in vitro studies used microspheres (scaffold free tissue construct) to close the critical size bone defects. They found osteogenically differentiated microspheres with outgrowing cells which can be used to fill up bone defects. This new procedure has added advantage of permitting the transplantation of more cells and better integrity as compared to cell suspensions or gels. ${ }^{36}$

Stem cells isolated from SHED has significantly promoted wound healing in nude mice, thereby 
proving that deciduous teeth can be utilized for the treatment of chronic wounds. This application can be extended into oromaxillofacial region to enhance wound healing. ${ }^{36}$

\section{Tooth regeneration}

The regeneration of adult teeth will be possible in future with the newer advancement in stem cell therapy and tissue engineering ${ }^{37}$ and these will be better fitting and provide a good alternative tool for dental implants.

Experimental studies with animal models have shown that the tooth crown structure can be regenerated using tissue engineering techniques that combine stem cells and biodegradable scaffolds. ${ }^{38}$ Epithelial mesenchymal interactions are mandatory in tooth development. "These interactions are characterized by the reciprocal exchange of signals between these two native germ layer tissues and result in the emergence of unique terminal phenotypes with their supporting cells". ${ }^{39}$

Tooth regeneration involves three key elements which include

- Inductive morphogenes

- Stem cells

- Scaffold

Steps involved in regeneration of tooth areHarvesting and expansion of

1. Adult stem cells.

2. Seeding the stem cells into scaffold which provides optimized environment.

3. Cells are instructed with targeted soluble molecular signals spatially.

4. Confirming the gene expression profile of the cells for next stage in odontogenesis. ${ }^{40}$

Duailibi et $\mathrm{al}^{41}$ in their experimental studies were able to form tooth structures from single cell suspensions of cultured rat tooth bud cells. They demonstrated that bioengineered rat teeth can be developed in 12 weeks with PGA and PLGA scaffold.

Honda et $\mathrm{al}^{42}$ developed tissue engineered teeth, when implanted into omentum of rat using porcine tooth bud cells and PGA fiber mesh scaffold that resembles the model of odontogenesis. ${ }^{42}$

\section{CONCLUSION}

The future of dentistry will be more of regenerative based, where patients own cells can be used to treat diseases. Stem cell therapy has got a paramount role as a future treatment modality in dentistry. Regenerative dentistry will have to go in pace with regenerative medicine. On the other hand, stem cells should be differentiated to the appropriate cell types before they can be used clinically, otherwise it might lead to deleterious effects. Determining the role of local conditions such as the type of scaffold and the presence of the microorganisms should be very carefully analyzed. Longer patient follow up is needed to study the life time of regenerated tissue.

\section{REFERENCES}

1 Slack JM. Origin of stem cells in organogenesis. Science 2008;322: 1498-501.

2 Langer R, Vacanti JP. Tissue engineering. Science 1993;260:920-6.

3 Kaigler D, Mooney D. Tissue engineering's impact on dentistry. J Dent Educ 2001;65:456-62.

4 Koyano K. Toward a new era in prosthodontic medicine. J Prosthodont Res 2012;56:1-2.

5 Kirkwood KL. Periodontal diseases and oral bone loss. In: Rosen CJ, editor. Primer on the metabolic bone diseases and disorders of mineral metabolism. 7th ed., Washington, DC: American Society for Bone and Mineral Research; 2008. p. 510-3.

6 Atwood DA. Reduction of residual ridges: a major oral disease entity. J Prosthet Dent 1971;26:266-79.

7 Darby I, Chen S, De Poi R. Ridge preservation: what is it and when should it be considered. Aust Dent J 2008;53:11-21.

8 Egusa H, Saeki M, Doi M, Fukuyasu S, Matsumoto T, Kamisaki Y. A small-molecule approach to bone regenerative medicine in dentistry. J Oral Biosci 2010;52:107-18.

9 Egusa H. IPS cells in dentistry. Clin Calcium 2012;22:67-73.

10 Izumi Y, Aoki A, Yamada Y, Kobayashi H, Iwata T, Akizuki T. Current and future periodontal tissue engineering. Periodontology 2000 2011;56:166-87.

11 Yamada Y, Ueda M, Hibi H, Baba S. A novel approach to periodontal tissue regeneration with mesenchymal stem cells and platelet-rich plasma using tissue engineering technology: a clinical case report. Int J Periodontics Restorative Dent 2006;26:363-9.

12 Ueda M, Yamada Y, Kagami H, Hibi H. Injectable bone applied for ridge augmentation and dental implant placement: human progress study. Implant Dent 2008;17:82-90.

13 Yamada Y, Nakamura S, Ito K, Kohgo T, Hibi H, Nagasaka T. Injectable tissue-engineered bone using autogenous bone marrow-derived stromal cells for maxillary sinus augmentation: clinical application report from a 2-6-year follow-up. Tissue Eng Part A 2008;14:1699-707.

14 Lombaert IM, Knox SM, Hoffman MP. Salivary gland progenitor cell biology provides a rationale for therapeutic salivary gland regeneration. Oral Dis 2011;17:445-448.

15 Luxameechanporn T, Hadlock T, Shyu J, Cowan D, Faquin W, Varvares M. Successful myoblast transplantation in rat tongue reconstruction. Head Neck 2006;28:517-24. 
16 Shah R, Sinanan AC, Knowles JC, Hunt NP, Lewis MP. Craniofacial muscle engineering using a 3-dimensional phosphate glass fibre construct. Biomaterials 2005; 26:1497-505.

17 Dormer NH, Busaidy K, Berkland CJ, Detamore MS. Osteochondral interface regeneration of rabbit mandibular condyle with bioactive signal gradients. J Oral Maxillofac Surg 2011;69:50-7.

18 Gardner RL. Stem cells: Potency, plasticity and public perception. JAnat 2002;200:277-82.

19 Hayflick L. The limited in vitro lifetime of human diploid cell strains. Exp Cell Res 1965;37:614-36.

20 Gurdon JB, Byrne JA. The first half-century of nuclear transplantation. Proc Natl Acad Sci U S A 2003;100:8048-52.

21 Thomson JA, Itskovitz-Eldor J, Shapiro SS, Waknitz MA, Swiergiel JJ, Marshall VS. Embryonic stem cell lines derived from human blastocysts. Science 1998;282:1145-7.

22 Keller GM. In vitro differentiation of embryonic stem cells. Curr Opin Cell Biol 1995;7:862-9.

23 Fortier LA. Stem cells, classifications, controversies and clinical applications. Vet Surg 2005;34:415-23.

24 Takahashi K, Yamanaka S. Induction of pluripotent stem cells from mouse embryonic and adult fibroblast cultures by defined factors. Cell 2006; 126:663-76.

25 Zuk PA, Zhu M, Mizuno H, Huang J, Futrell JW, Katz AJ. Multilineage cells from human adipose tissue:Implications for cell- based therapies. Tissue Eng 2001;7:211-28.

26 Gronthos S, Mankani M, Brahim J, Robey PG, Shi S. Postnatal human dental pulp stem cells (DPSCs) in vitro and in vivo. Proc Natl Acad Sci U S A 2000;97:13625-30.

27 Miura M, Gronthos S, Zhao M, Lu B, Fisher LW, Robey PG. SHED: Stem cells from human exfoliateddeciduous teeth. Proc Natl Acad Sci U S A 2003;100:5807-5810.

28 Seo BM, Miura M, Gronthos S, Bartold PM, Batouli S, Brahim J. Investigation of multipotent postnatal stem cells from human periodontal ligament. Lancet 2004; 364:149-55.

29 Sonoyama W, Liu Y, Yamaza T, Tuan RS, Wang S, Shi S, et al. Characterization of the apical papilla and its residing stem cells from human immature permanent teeth: A pilot study. $\mathbf{J}$ Endod 2008;34:166-71.

30 Morsczeck C, Götz W, Schierholz J, Zeilhofer F, Kühn U, Möhl C, et al. Isolation of precursor cells (PCs) from human dental follicle of wisdom teeth. Matrix Biol 2005;24:155-65.

31 Huang GT, Gronthos S, Shi S. Mesenchymal stem cells derived from dental tissues vs. those from other sources: Their biology and role in regenerative medicine. J Dent Res 2009;88:792-806.

32 d'Aquino R, De Rosa A, Lanza V, Tirino V, Laino L, Graziano A. Human mandible bone defect repair by the grafting of dental pulp stem/progenitor cells and collagen sponge biocomplexes. Eur Cell Mater 2009;18:75-83.

33 Lendeckel S, Jödicke A, Christophis P, Heidinger K, Wolff J, Fraser JK. Autologous stem cells (adipose) and fibrin glue used to treat widespread traumatic calvarial defects: Case report. J Craniomaxillofac Surg 2004;32:370-3 .
34 Alhadlaq A, Tang M, Mao JJ. Engineered adipose tissue from human mesenchymal stem cells maintains predefined shape and dimension: Implications in soft tissue augmentation and reconstruction. Tissue Eng 2005; 11:556-66.

35 Langenbach F, Naujoks C, Kersten-Thiele PV, Berr K, Depprich RA, Kübler NR. Osteogenic differentiation influences stem cell migration out of scaffold-free microspheres. Tissue Eng Part A 2010;16:759-66.

36 Nishino Y, Yamada Y, Ebisawa K, Nakamura S, Okabe K, Umemura E. Stem cells from human exfoliated deciduous teeth (SHED) enhance wound healing and the possibility of novel cell therapy. Cytotherapy 2011;13:598-605.

37 Honda MJ, Fong H, Iwatsuki S, Sumita Y, Sarikaya M. Toothforming potential in embryonic and postnatal tooth bud cells. Med Mol Morphol 2008;41:183-92.

38 Nakahara T, Ide Y. Tooth regeneration: Implications for the use of bioengineered organs in first-wave organ replacement. Hum Cell 2007;20:63-70.

39 Thesleff I, Sharpe P. Signalling networks regulating dental development. Mech Dev 1997;67:111-23.

40 Snead ML. Whole-tooth regeneration: It takes a village of scientists, clinicians, and patients. J Dent Educ 2008;72:90311.

41 Duailibi MT, Duailibi SE, Young CS, Bartlett JD, Vacanti JP, Yelick PC. Bioengineered teeth from cultured rat tooth bud cells. J Dent Res 2004;83:523-8.

42 Honda MJ, Sumita Y, Kagami H, Ueda M. Histological and Immunohistochemical studies of tissue engineered odontogenesis. Arch Histol Cytol 2005;68:89-101.

43 Mao JJ, Giannobile WV, Helms JA, Hollister SJ, Krebsbach $\mathrm{PH}$, Longaker MT, Shi S. Craniofacial tissue engineering by stem cells. J Dent Res 2006;85(11):966-79.

44 Stanko P, Kaiserova K, Altanerova V, Altaner C. Comparison of human mesenchymal stem cells derived from dental pulp, bone marrow, adipose tissue, and umbilical cord tissue by gene expression. J Endod 2009;35:1536-42.

45 Pittenger MF, Mackay AM, Beck SC. Multilineage potential of adult human mesenchymal stem cells. Science 1999;284:143-7.

46 Miura M, Gronthos S, Zhao M. SHED: Stem cells from human exfoliated deciduous teeth. Proc Natl Acad Sci USA 2003;100:5807-12.

47 Mitsiadis TA, Rahiotis C. Parallels between tooth development and repair: conserved molecular mechanisms following carious and dental injury. J Dent Res 2004;83:896-902.

48 Sonoyama W, Liu Y, Fang D. Mesenchymal stem cell mediated functional tooth regeneration in swine. PLoS ONE 2006;1:79.

49 Komine A, Suenaga M, Nakao K, Tsuji T, Tomooka Y. Tooth regeneration from newly established cell lines from a molar tooth germ epithelium. Biochem Biophys Res Commun 2007; 355:758-63.

50 Thesleff I, Wang XP, Suomalainen M. Regulation of epithelial stem cells in tooth regeneration. C R Biol 2007;330:561-4. 